\title{
Service Quality of Outpatient Department in a District General Hospital - Sri Lanka: The patients' perspective
}

\author{
${ }^{1}$ Francis U.M.G.S, ${ }^{2}$ Perera U. A. A. S, ${ }^{3}$ Jayakody J.A. P \\ ${ }^{1}$ Registrar in Medical Administration, MBBS, MBA (LMU), MSc, Dip. HCQPS, Dip. BCS \\ ${ }^{2}$ Senior Registrars in Medical Administration, MBBS, DIPPCA, MSc, MD \\ ${ }^{3}$ Senior Registrars in Medical Administration, MBBS, DIPPCA, MSc, MD
}

DOI: 10.29322/IJSRP.11.01.2021.p10985

http://dx.doi.org/10.29322/IJSRP.11.01.2021.p10985

\begin{abstract}
Access to timely, acceptable, and affordable health care of appropriate quality is a fundamental human right. Importance of service quality in healthcare has increased in the recent past due to its benefits to the patients and the healthcare provider. Assessment of the patients' perspective regarding the health care quality especially infrequently utilized services such as Out-patient department (OPD) was a timely need to identify the service quality gaps and to take action to improve the level of quality.

The study adopted a quantitative mono-method using a 'survey' strategy. A descriptive cross-sectional study was conducted. An interviewer-administered structured questionnaire was used to collect data regarding patients expectations and perception about the OPD services adopting the SERVQUAL model.

The study found that overall expectations regarding service quality were 'high' while perceived quality was " average'. Significant service quality gaps were observed in overall service quality, all assessed items and all five dimensions of service quality.

Establishing a periodic review system to assess patients' expectations, perceptions and effectiveness of quality improvement measures were recommended. Training staff on 'soft skills', digitalization of OPD procedures and medical records and proper maintenance of hospital infrastructure and equipment were also recommended.
\end{abstract}

Index Terms- Out-Patient Department, Service Quality, Patients' expectations, patients' perception, Service Quality Gap

\section{INTRODUCTION}

$\mathrm{T}$ 1.1 Introduction to the Research topic he constitution of World Health Organization (WHO) broadly defined health as "a state of complete physical, mental, and social well-being and not merely the absence of disease or infirmity' (World Health Organization, 2017). However, the right to health includes not only the medical care but also access to timely, acceptable, and affordable health care of appropriate quality (World Health Organization, 2017). Hence, health care providers need to ensure that all these aspects of quality healthcare are given attention when planning and providing health care to its community.

Service quality in healthcare has been defined and modeled by many authors over the past four decades. Donabedian (1980) defined healthcare quality as "the application of medical science and technology in a manner that maximizes its benefit to health without correspondingly increasing the risk". It is distinguished three main aspects of healthcare quality namely, technical quality, interpersonal quality and amenities accommodating patient needs and preferences and physical surroundings and organization attribute.

\subsection{Significance of the Study}

Service quality not only benefits the patients. The importance of service quality in health care has been growing for past few decades as means of reducing operating costs, improving productivity, improving health outcomes and meeting customer expectations leading to higher levels of organizational performance and long-lasting relationships with customers, employees and suppliers (Mosadeghrad, 2011). Hence, assessing the service quality and taking measures to improve service quality are prime responsibilities of healthcare planners and managers.

Kegalle hospital is a District General Hospital (DGH) with strength of 735 beds and an average daily Outpatient attendance of 850 patients. Having a highly utilized OPD not only provided a good opportunity to study a significant number of patients but also to obtain a comprehensive understanding of the patients' expectations and perception regarding service quality. Assessment of the service quality in the hospital paved the path for the hospital management to improve the deficient areas in OPD services which were not recognized before the study. 
The authors, being medical administrators could understand the patients' perspective of service quality through this study which helped to incorporate the evidence to improve the out-patient services in a patient-friendly manner in health institutions. The study assessed the Service Quality of Outpatient Department in District General Hospital Kegalle. The service quality was assessed in the view of patents' expectations and perceptions regarding the service quality of the Outpatient services provided by the hospital.

\section{LITERATURE}

SERVQUAL model developed by Parasuraman et al. (1985) is a model used to assess service quality in a variety of industries. Five service quality dimensions namely, reliability, assurance, tangibles, empathy and responsiveness are included in the SERVQUAL model. Tangibles involve the appearance of physical facilities, equipment, personnel and communication materials while reliability ensures providing the promised service dependably and accurately. Tangibles in the healthcare set up include the physical facilities, equipment and appearance of healthcare personnel (Chaniotakis and Lymperopoulos, 2009).

A study done in an Indian peripheral hospital revealed that patients had high expectations regarding the tangibility dimension and the perceived quality of the same was significantly low. Availability of equipment, the hygienic appearance of the physical facilities, cleanliness and staff being well dressed, and pleasant looking showed a significant negative gap about expected and perceived service quality (Chakravarty, 2011).

Chakravarty (2011) concluded that the negative service quality gap of reliability dimension was not significant in his study conducted in a peripheral hospital OPD in India. Dependable OPD services and accurate record-keeping were satisfactory to the patients as a gap was not observed in expectation and perception. Even though not significant, negative gaps were observed in the punctuality of staff and sympathetic attendance to patients.

According to Chakravarthy (2011), the highest quality expectation of OPD patients in a peripheral hospital in India was observed for 'prompt response to patients' requests. Further, Significant negative gaps were observed in the same aspect and promptness of service. Overall, the study revealed that there was a significant negative service quality gap in the responsiveness dimension.

Study in Indian peripheral hospital OPD found that the negative service quality gap seen in assurance dimension was not significant including the trustworthiness of staff and patients feeling safe while being treated (Chakravarty, 2011).

A study conducted among 50 patients seeking care at a peripheral hospital OPD in India revealed a negative service quality gap in empathy dimension which was not statistically significant. Interestingly, only two items that showed a positive service quality gap in the study were 'paying individual attention' and 'readiness of personal attention to the patients' which were assessed under the empathy dimension (Chakravarty, 2011).

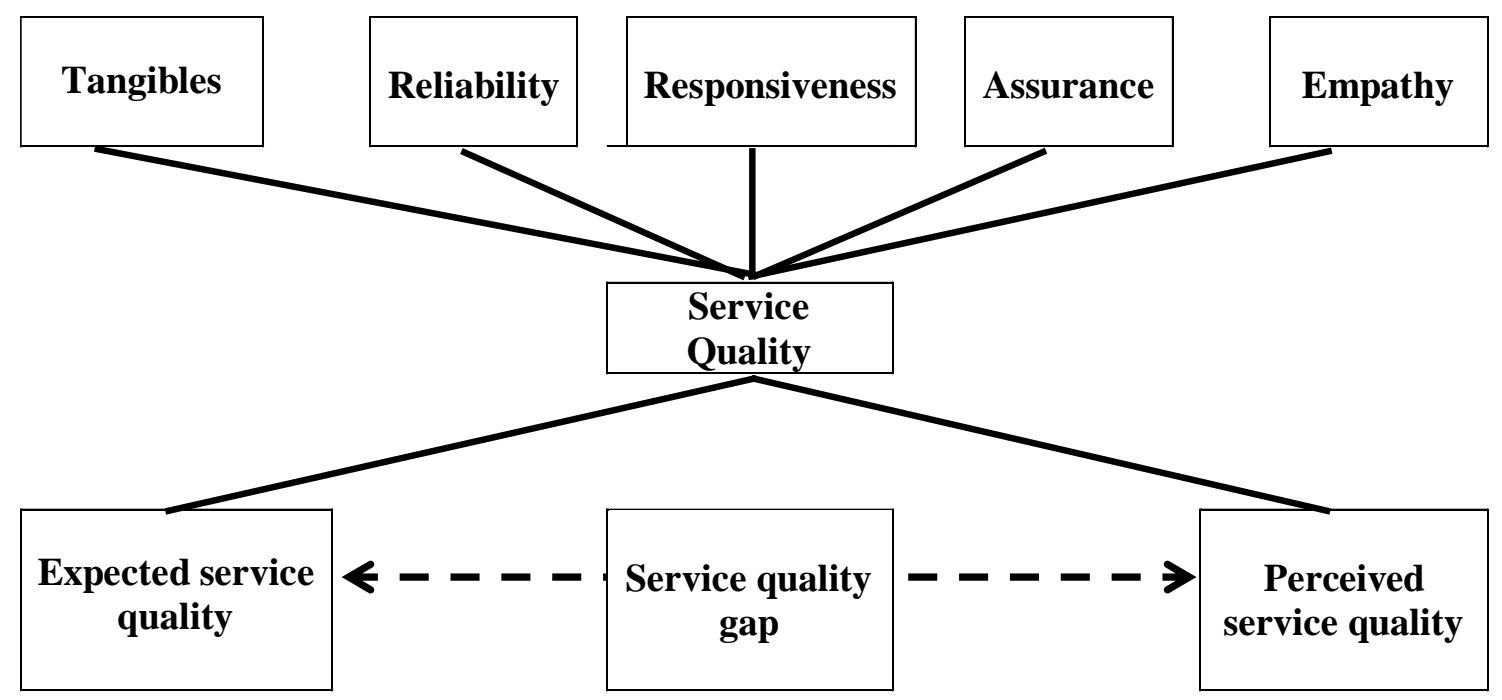

\subsection{Objectives Main Objective}

This publication is licensed under Creative Commons Attribution CC BY. 
To assess the service quality of outpatient department in District general Hospital -Kegalle

\section{Specific objectives}

I. To assess the patients' expectations of service quality in the outpatient department in District general Hospital - Kegalle

II. To assess the patients' perceptions of service quality in the outpatient department in District general Hospital - Kegalle

III. To determine the service quality gaps in the outpatient department in District general Hospital - Kegalle

IV. To give recommendations to improve the service quality of the outpatient department in District general Hospital - Kegalle

\section{METHODS}

The descriptive study involved the philosophy of positivism as it was based on observable social reality and generalization and conducted in a value-free manner (Saunders et al., 2012).

It had a deductive approach as it was based on the existing theories and concepts on service quality which were operationalzed in a way to quantitatively measure the service quality and generalize at the end of the study.

A survey strategy was used to collect quantitative data from a sample of 422 patients under 20 questions and to analyze the relationship between the expected and perceived service quality in OPD services. Only a structured questionnaire was administered as the data collection tool and quantitative data was collected in terms of mean expectation score and mean perception score. Hence, the mono method was adopted for data collection and analysis. Considering the time and resource constraints the time horizon of the study was limited to a cross-sectional study where a sample of patients coming to the OPD for 7 days was selected and their opinion on expected and perceived service quality was obtained once using the questionnaire.

\subsection{Sample rationale}

The hospital was purposively selected since it being a District General Hospital that provides outpatient care for a significantly large population in the catchment area.

The study population was identified as the patients seeking outpatient care from the OPD of District General hospital Kegalle.

Therefore, sample size was calculated as follows allowing $5 \%$ of margin of error.

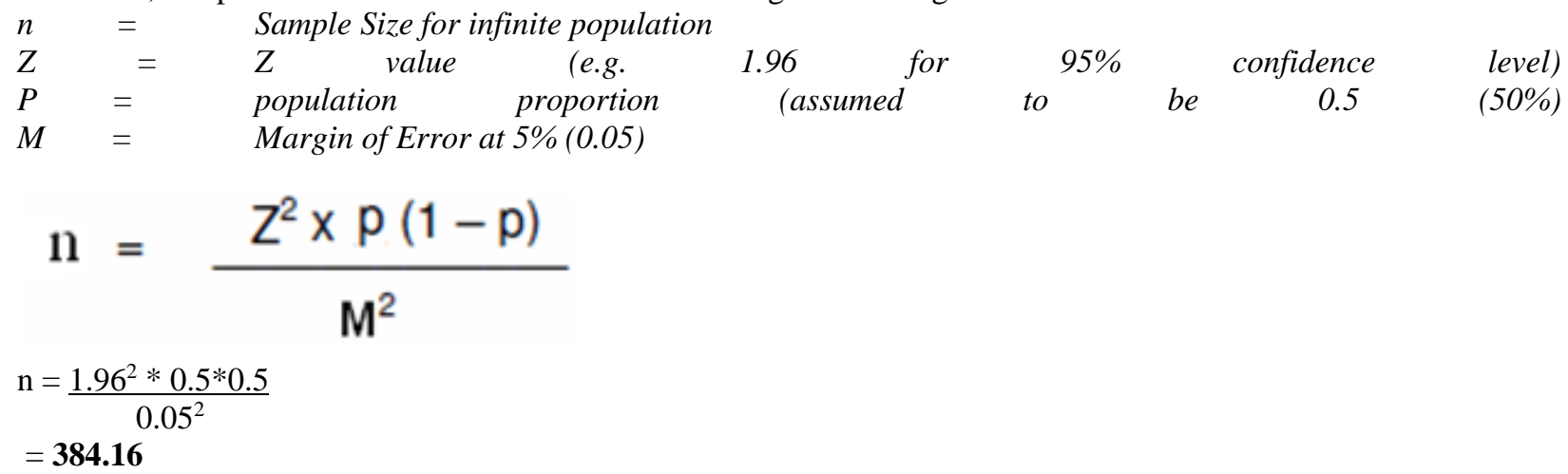

Average daily OPD attendance of District General Hospital Kegalle amounted to 850 encounters. To incorporate a daily variation of out-patients, the sampling frame was chosen as out-patients attending the OPD for 7 consecutive days. Systematic sampling was adopted.

Sampling interval $=\underline{\text { Sampling frame }}$

$$
\begin{aligned}
& \text { Sample size } \\
& =\frac{850 * 7}{384} \\
& =15.49
\end{aligned}
$$

Therefore every $15^{\text {th }}$ patient attending the OPD was recruited to the sample.

$\underline{\text { Inclusion criteria }}$ 
Patients aged more than 18 years and in-case of pediatric patients; guardian accompanying the child was selected for the sample.

\subsection{Data collection instruments}

A validated interviewer-administered structured questionnaire based on the SERVQUAL model was obtained from the literature review and modified to suit the local set up (Parasuraman et al., 1985). It included 20 paired questions under five service quality dimensions. Five-point Likert scale was used to record the responses of the patients. Responses were collected about expected service quality and perceived service quality in each service quality dimension as summarized in Table 01.

Patients' expectations in Tangibility dimension

The patients' expectations regarding tangibles were assessed concerning the appearance of;

i. OPD, OPD furniture and seating - clean, neat and visually appealing

ii. Medical equipment - modern looking

iii. Staff - Clean, neat and well dressed and

iv. Prescriptions, investigation forms and other material- Clean, neat and visually appealing.

Patients' expectations regarding Reliability dimension

The reliability of the OPD services was assessed concerning;

v. Punctuality of staff and being at the place of duty on time

vi. Listening to patients and showing genuine interest to solve them

vii. Communication of medical advice and information regarding treatment clearly and correctly and

viii. Providing services correct for the first time.

Patients' expectations regarding Responsiveness dimension

The responsiveness of the OPD services was assessed with;

ix. Provision of services on time with reasonable waiting time

x. Easiness and convenience in patient registration and queue management

xi. Promptness in attending to patients' requests

xii. The willingness of staff to help customers all the time

Patients' expectations regarding Assurance dimension

The assurance of the OPD services was assessed concerning;

xiii. Staff is knowledgeable and competent to provide OPD services

xiv. Staff being trustworthy and Patients feeling safe while being treated at the OPD

$\mathrm{xv}$. Staff is polite and respecting the privacy of patients

Patients' expectations regarding Empathy dimension

The empathy of the OPD services was assessed with;

xvi. Staff paying individual attention to the patients

xvii. Staff is aware of the specific needs of the patients

xviii. Staff acting for the best interest of the patient

xix. Adequacy of time given to discuss patients' matters at the OPD and

xx. Functioning the OPD at convenient hours to all patients

Table 01: Scoring system in the questionnaire

\begin{tabular}{|c|c|c|c|}
\hline $\begin{array}{l}\text { Service Quality } \\
\text { Dimension }\end{array}$ & Question Numbers & $\begin{array}{l}\text { Patients' expected } \\
\text { service quality score }\end{array}$ & $\begin{array}{l}\text { Patients' Perceived } \\
\text { service quality score }\end{array}$ \\
\hline
\end{tabular}

\begin{tabular}{|c|c|c|c|}
\hline Tangibility & $1,2,3,4$ & \multirow{5}{*}{$\begin{array}{l}\text { 1- Strongly Disagree } \\
\text { 2-Disagree } \\
\text { 3- Neutral } \\
\text { 4- Agree } \\
\text { 5- Strongly Agree }\end{array}$} & \multirow{5}{*}{$\begin{array}{l}\text { 1- Strongly Disagree } \\
\text { 2-Disagree } \\
\text { 3- Neutral } \\
\text { 4- Agree } \\
\text { 5- Strongly Agree }\end{array}$} \\
\hline Reliability & $5,6,7,8$ & & \\
\hline Responsiveness & $9,10,11,12$ & & \\
\hline Assurance & $13,14,15$ & & \\
\hline Empathy & $16,17,18,19,20$ & & \\
\hline
\end{tabular}


$* * *$ Maximum score $=5$, Minimum Score $=1$

Analysis of the scores is described under data analysis.

\subsection{Data Access}

Permission was obtained from the Director of District General hospital - Kegalle for data collection.

\subsection{Data collection}

\subsubsection{Role of the researcher}

Data collection was conducted by two trained data collectors when patients were exiting the Outpatient department. Researcher bias was minimized by training the data collectors to be unbiased and adopting the systematic sampling method and structured questionnaire. An information sheet regarding the study was provided to the participants and time could clarify doubts. Informed written consent was obtained from the participants before data collection.

\subsubsection{Validity}

The questionnaire was already validated and tested in studies conducted worldwide. It was further validated by healthcare quality experts in the Directorate of Healthcare quality. Opinion on a director of healthcare quality and safety was consulted in modifying the questionnaire. It was pretested among a similar sample and modified according to the feedback. This ensured validity of the questions asked to obtain data.

\subsection{Data Analysis}

The raw data from the completed questionnaire were entered into Microsoft Excel spreadsheet and was analyzed using Microsoft Office- Excel - 2013 and SPSS version 21.

\section{Patients' expectations of service quality}

Patients' expectation of service quality was interpreted based on the Mean expectation score and the frequency of responses.

\section{Mean expectation score}

As discussed under data collection instruments, each response out of five responses has given a score (Refer to Table 01). Mean expectation score (MES) for each service quality dimension was calculated as follows;

MES of Tangibility $=\frac{\text { Q1 E score }+ \text { Q2 E score }+ \text { Q3 E score }+ \text { Q4 E score }}{4}$

MES of Reliability $=\frac{\text { Q5 E score }+ \text { Q6 E score }+ \text { Q7 E score }+ \text { Q8 E score }}{4}$

MES of Responsiveness $=\frac{\text { Q9 E score }+ \text { Q10 E score }+ \text { Q11 E score }+ \text { Q12 E score }}{4}$

MES of Assrance $=\frac{\mathrm{Q} 13 \mathrm{E} \text { score }+\mathrm{Q} 14 \mathrm{E} \text { score }+\mathrm{Q} 15 \text { E score }}{3}$

MES of Empathy $=\frac{\text { Q16 E score }+ \text { Q17 E score + Q18 E score + Q19 E score + Q20E score }}{4}$

Total Mean Expectation score and Mean expectation score for each item under service quality dimensions were also calculated.

Mean expectation score of service quality dimensions and each item was interpreted based on the following criteria.

Table 02: Criteria for interpretation of patients' expectation based on mean expectation score

\begin{tabular}{ll}
\hline Score & Patients' service quality expectation level \\
\hline Less than 3 & Low \\
\hline 3 to 3.99 & Average \\
\hline More than 3 & High \\
\hline
\end{tabular}

Frequency of responses

The service quality of each item in all five dimensions was assessed based on the frequency of responses using the following criteria. 
Table 03: Criteria for interpretation of patients' expectation based on the frequency of responses

\begin{tabular}{|c|c|c|c|}
\hline $\begin{array}{l}\text { Number of respondents } \\
\text { 'Agree' or Strongly agree' } \\
\text { on the item }\end{array}$ & Or & $\begin{array}{l}\text { Number of respondents } \\
\text { 'Disagree' or Strongly disagree' } \\
\text { on the item }\end{array}$ & $\begin{array}{l}\text { Patients' service quality } \\
\text { expectation level }\end{array}$ \\
\hline Less than $33 \%$ & & More than $66 \%$ & Low \\
\hline $33 \%$ to $66 \%$ & & $33 \%$ to $66 \%$ & Average \\
\hline More than $66 \%$ & & Less than $33 \%$ & High \\
\hline
\end{tabular}

Satisfying one criterion was considered adequate for interpretation of results.

Patients' perceived service quality

Similarly, Mean Perception Scores (MPS) were calculated as follows for each quality dimension.

MPS of Tangibility $=\frac{\text { Q1 P score }+ \text { Q2 P score }+ \text { Q3 P score }+ \text { Q4 P score }}{4}$

MPS of Reliability $=\frac{\text { Q5 P score + Q6 P score + Q7 P score + Q8 P score }}{4}$

MPS of Responsiveness $=\frac{\text { Q9 P score }+ \text { Q10 P score }+ \text { Q11 P score }+ \text { Q12 P score }}{4}$

MPS of Assrance $=\frac{\text { Q13 P score }+ \text { Q 14 Pscore }+ \text { Q15 P score }}{3}$

MPS of Empathy $=\frac{\text { Q16 P score }+ \text { Q17 P score }+ \text { Q18 P score }+ \text { Q19 P score + Q20P score }}{4}$

Mean perception score for each of 20 items under service quality dimensions was also calculated.

Mean perception score of service quality dimensions and each item was interpreted based on the following criteria.

Table 04: Criteria for interpretation of patients' perception

\begin{tabular}{ll}
\hline Score & Patients' perceived level of service quality \\
\hline Less than 3 & Low \\
\hline 3 to 3.99 & Average \\
\hline More than 3 & High \\
\hline
\end{tabular}

Frequency of responses

The service quality of each item in all five dimensions was assessed based on the frequency of responses using the following criteria.

Table 05: Criteria for interpretation of patients' perception based on the frequency of responses

\begin{tabular}{|c|c|c|c|}
\hline $\begin{array}{l}\text { Number of respondents } \\
\text { 'Agree' or Strongly agree' } \\
\text { on the item }\end{array}$ & Or & $\begin{array}{l}\text { Number of respondents 'Disagree' or } \\
\text { Strongly disagree' on the item }\end{array}$ & $\begin{array}{l}\text { Patients' perceived level } \\
\text { of service quality }\end{array}$ \\
\hline Less than $33 \%$ & & More than $66 \%$ & Low \\
\hline $33 \%$ to $66 \%$ & & $33 \%$ to $66 \%$ & Average \\
\hline More than $66 \%$ & & Less than $33 \%$ & High \\
\hline
\end{tabular}

Service quality gap 
According to Parasuraman et al. (1985), the service quality gap is the difference between expected quality and perceived quality.

Service Quality Gap = Perception - Expectation

SERVQUAL score $=$ Mean Perception score - Mean Expectation Score

The service quality gap was interpreted based on the following criteria.

Table 06: Criteria for interpretation of service quality gap

\begin{tabular}{ll}
\hline SERVQUAL SCORE & Service quality \\
\hline Negative Score & Poor - Patients are dissatisfied \\
\hline Zero & No gap -Patients are Satisfied \\
\hline Positive Score & High - Patients are delighted \\
\hline
\end{tabular}

A positive quality gap score indicates a better service quality compared to expectations of the respondent while a negative score indicates a worse perceived quality compared to the expectations of the respondent.

\subsection{Ethical considerations}

There was no maleficence attached to the study. Care was taken not to include sensitive questions in the questionnaire. Data collection was conducted ethically with minimum interference to the care of the patient. Informed written consent was taken from the participants and the confidentiality of the data was maintained until the purpose was achieved. The data was kept under the custody of the principal investigator and will be destroyed after the purpose is achieved. Individual data will not be divulged to any party or published without prior permission from the relevant participant.

\section{INVESTIGATION AND ANALYSIS}

\subsection{Introduction}

The total number of 384 questionnaires was distributed among the consenting patients and 358questionnaires were received with a non-responder rate of $6.77 \%$.

The mean and median age of the respondents was 40 years. Age ranged from 18 years to 73 years as pediatric patients were excluded from the sample. Majority of the sample were females which amounted to 58.9\% $(\mathrm{n}=211)$. Most of the respondents were married $(n=247,69 \%)$ while $24 \%(n=86)$ were unmarried. $48.6 \%, 24.3 \%, 13.1 \%$ of the sample were educated up to A/Level, O/level and grade 8 respectively. None had post-graduate qualifications while only $4.7 \%$ were recorded to be graduates.

Results are described under three sections corresponding with the first 3 objectives of the study.

\subsection{Service quality expectations of patients seeking outpatient care}

Patients' service quality expectations are described under each of the five service quality dimensions in the SERVQUAL model.

Table 07: Distribution of patients' Mean expectation scores according to service quality dimension (Author generated based on survey data)

\begin{tabular}{llll}
\hline Service quality dimension & MES & Rank & $\begin{array}{l}\text { Level of Patients' } \\
\text { expectations }\end{array}$ \\
\hline Tangibility & 4.05 & 2 & High \\
Reliability & 4.08 & 1 & High \\
Responsiveness & 4.01 & 3 & High \\
Assurance & 3.97 & 4 & Average \\
Empathy & 3.96 & 5 & Average \\
\hline Total MES & $\mathbf{4 . 0 2}$ & & High \\
\hline
\end{tabular}

Reliability had the highest mean expectation score (4.08) while Empathy dimension (3.96) had the least Mean expectation score. Patients' service quality expectations were 'high' for Reliability, Tangibility and Responsiveness 
dimensions and 'Average' for Assurance and Empathy dimensions (refer Table 02). Despite that, it was observed that Mean expectation Score for all five dimensions was around 4 (3.96 to 4.08). Overall expectation level was 'high' as the Total Mean expectation Score was 4.02.

Table 08 shows the detailed analysis of patents' expectations based on the mean expectation score of each item of service quality in all five service quality dimensions.

Table 08: Distribution of patients' expectations according to items in service quality dimensions (Author generated based on survey data)

\begin{tabular}{|c|c|c|c|c|}
\hline Item & & MES & Rank & $\begin{array}{l}\text { Expectation } \\
\text { level }\end{array}$ \\
\hline i. & $\begin{array}{l}\text { The appearance of OPD, OPD furniture and seating - clean, neat and } \\
\text { visually appealing }\end{array}$ & 4.00 & 8 & High \\
\hline ii. & The appearance of medical equipment - modern looking & 4.03 & 6 & High \\
\hline iii. & The appearance of Staff - Clean, neat and well dressed and & 4.10 & 3 & High \\
\hline iv. & $\begin{array}{l}\text { The appearance of prescriptions, investigation forms and other } \\
\text { material- Clean, neat and visually appealing. }\end{array}$ & 4.07 & 4 & High \\
\hline V. & Punctuality of staff and being at the place of duty on time & 4.18 & 1 & High \\
\hline vi. & Listening to patients and showing genuine interest to solve them & 4.15 & 2 & High \\
\hline vii. & $\begin{array}{l}\text { Communication of medical advice and information regarding treatment } \\
\text { clearly and correctly and }\end{array}$ & 3.94 & 12 & Average \\
\hline viii. & Providing services correct for the first time. & 4.05 & 5 & High \\
\hline ix. & Provision of services on time with reasonable waiting time & 4.00 & 8 & High \\
\hline $\mathrm{x}$. & $\begin{array}{l}\text { Easiness and convenience in patient registration and queue } \\
\text { management }\end{array}$ & 4.02 & 7 & High \\
\hline xi. & Promptness in attending to patients' requests & 4.02 & 7 & High \\
\hline xii. & The willingness of staff to help customers all the time & 3.98 & 9 & Average \\
\hline xiii. & Staff is knowledgeable and competent to provide OPD services & 4.05 & 5 & High \\
\hline xiv. & $\begin{array}{l}\text { Staff being trustworthy and Patients feeling safe while being treated at } \\
\text { the OPD }\end{array}$ & 3.90 & 14 & Average \\
\hline XV. & Staff is polite and respecting the privacy of patients & 3.97 & 10 & Average \\
\hline xvi. & Staff paying individual attention to the patients & 3.93 & 13 & Average \\
\hline xvii. & Staff is aware of the specific needs of the patients & 4.0 & 8 & High \\
\hline xviii. & Staff acting for the best interest of the patient & 3.97 & 10 & Average \\
\hline xix. & Adequacy of time given to discuss patients' matters at the OPD and & 3.94 & 12 & Average \\
\hline $\mathrm{xx}$ & Functioning the OPD at convenient hours to all patients & 3.95 & 11 & Average \\
\hline
\end{tabular}

According to the mean expectation score, respondents had the highest expectations (4.18) in punctuality of the staff. Further, listening to the patients' problems and showing sincere interest to solve them which was also an item in the reliability dimension had the next highest expectation score (4.15). Staff being trustworthy and patient feeling safe while being treated at OPD carried the least mean expectation score (3.93) still recording an 'average' level of expectations. 'Clear and correct communication of medical advice and information regarding treatment, the willingness of staff to help customers all the time and Staff being polite and respecting the privacy of patients' were also expected in 'average' level by the respondents. While all 4 items of tangibility had 'high' level of expectations, 4 out of 5 items in the empathy dimension were expected in the 'average' level by the respondents.

Highest mean expectation score of 4.18 was recorded for the punctuality of staff. Listening to the patients' problems and showing genuine interest to solve them, Staff being well dressed and neat and prescriptions and forms being clean and visually appealing also had 4.15, 4.10 and 4.07 respectively. Least expected service quality aspect was staff being trustworthy and patients' feeling safe while being treated which accounted for a score of 3.90 . However, all items assessed in the study had a mean expectation score indicating high levels of patient expectations in all.

The findings were analyzed based on the frequency of responses and presented in Figure 02. The interpretations are based on the criteria mentioned in 'Data analysis' subsection in Chapter 3 (refer to Table 03). 


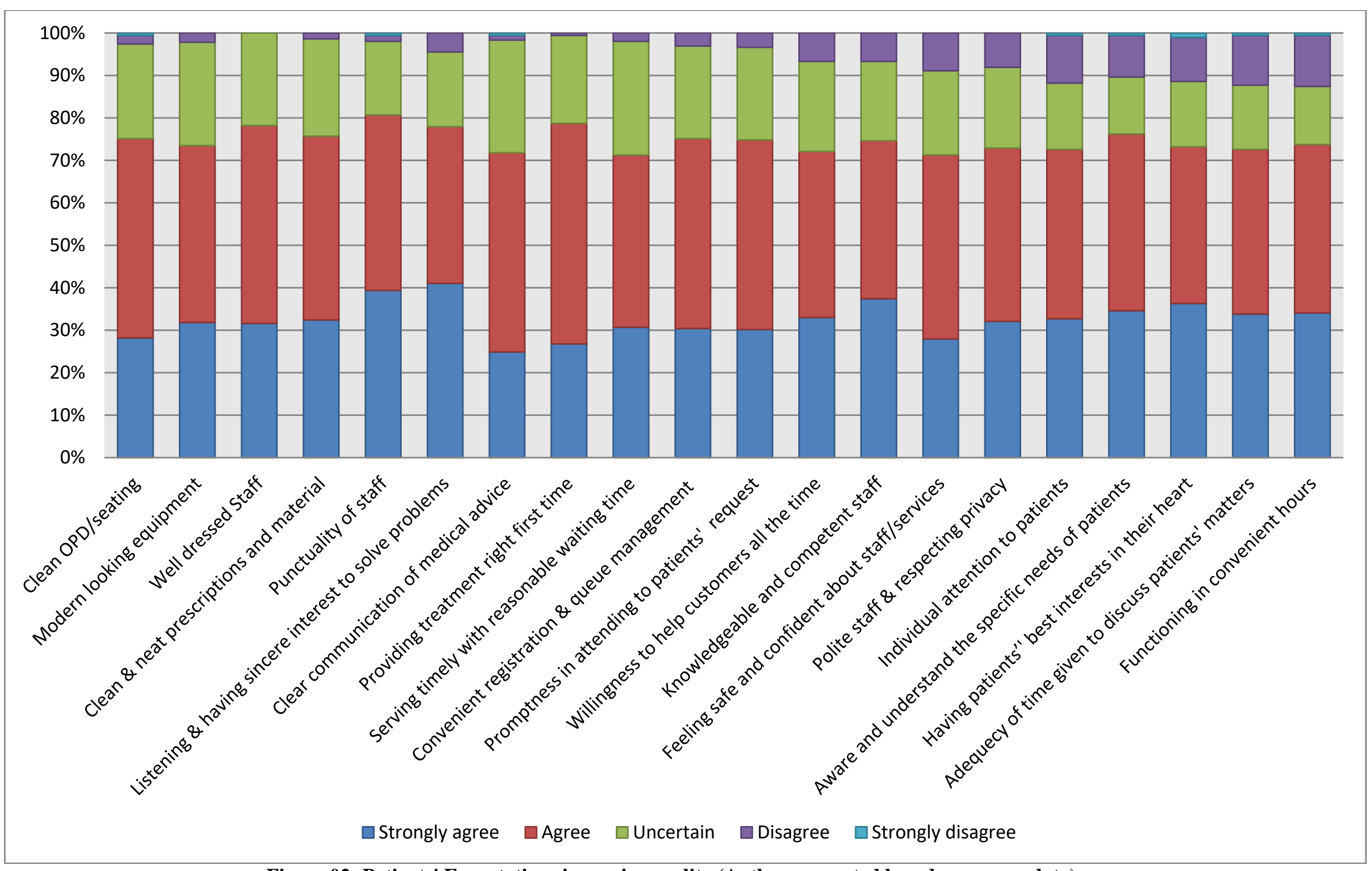

Figure 02: Patients' Expectations in service quality (Author generated based on survey data) 
Around $40 \%$ of the respondents strongly agreed that OPD staff should listen to the patient's problems and show sincere interest to solve them $(41.1 \%, \mathrm{n}=147)$ and be punctual $(39.4 \%, \mathrm{n}=141)$. Staff being knowledgeable and competent $(37.4 \%, \mathrm{n}=134)$ and acting for the best interest of the patients $(36.3 \%, \mathrm{n}=130)$ also had high expectations as more than one-third of the respondents strongly agreed that these aspects should present in the OPD.

More than half of the respondents expressed their opinion as 'agree' for the provision of services the right first time.

Considering 'agree' and strongly agree' responses together, around $80 \%$ of the respondents expected OPD staff to be punctual $(80.7 \%)$ and provide treatment right the first time. Similarly, more than $70 \%$ of the respondents agreed or strongly agreed that all aspects surveyed under each service quality should present in the OPD indicating high levels of patient expectations.

In summary, all items had 'high' expectation levels as more than $66 \%$ of the respondents believed that these items should present in OPD services (Refer to table 03).

\subsection{Service quality perceptions of patients seeking outpatient care}

Perceived service quality of the OPD of DGH Kegalle is described under each of five quality dimensions.

Table 09: Patients' perception regarding service quality according to service quality dimensions

\begin{tabular}{llll}
\hline Service quality dimension & Mean Perception Score & Rank & Perceived level of service quality \\
\hline Tangibility & 3.16 & 1 & Average \\
Reliability & 3.12 & 2 & Average \\
Responsiveness & 2.99 & 3 & Low \\
Assurance & 2.97 & 4 & Low \\
Empathy & 2.78 & 5 & Low \\
\hline Total MPS & 3.00 & & Average \\
\hline
\end{tabular}

Highest mean perception score (3.16) was recorded for tangibility dimension. A least mean score was perceived for empathy dimension (2.78). Perceived quality was less than 3 for responsiveness, assurance and empathy indicating 'low' levels of perceived quality. None of the dimensions had 'high' levels of service quality. Tangibility and reliability were perceived to have an average level of service quality. Total perception score for all five dimensions was3.0 indicating an 'average' level of perceived quality in OPD services.

Perceived service quality of each item was further analyzed based on the mean perception score as summarized in the following table.

Table 10: Patients' perception of service quality according to items

\begin{tabular}{|c|c|c|c|c|}
\hline Item & & $\begin{array}{l}\text { Mean } \\
\text { Perception } \\
\text { Score }\end{array}$ & Rank & $\begin{array}{l}\text { Perceived } \\
\text { level of } \\
\text { services } \\
\text { quality }\end{array}$ \\
\hline i. & $\begin{array}{l}\text { The appearance of OPD, OPD furniture and seating - clean, } \\
\text { neat and visually appealing }\end{array}$ & 3.12 & 5 & Average \\
\hline ii. & The appearance of medical equipment - modern looking & 3.15 & 4 & Average \\
\hline iii. & The appearance of Staff - Clean, neat and well dressed and & 3.25 & 2 & Average \\
\hline iv. & $\begin{array}{l}\text { The appearance of prescriptions, investigation forms and other } \\
\text { material- Clean, neat and visually appealing. }\end{array}$ & 3.12 & 5 & Average \\
\hline v. & Punctuality of staff and being at the place of duty on time & 3.04 & 8 & Average \\
\hline vi. & $\begin{array}{l}\text { Listening to patients and showing genuine interest to solve } \\
\text { them }\end{array}$ & 2.90 & 13 & Low \\
\hline vii. & $\begin{array}{l}\text { Communication of medical advice and information regarding } \\
\text { treatment clearly and correctly and }\end{array}$ & 3.22 & 3 & Average \\
\hline viii. & Providing services correct for the first time. & 3.31 & 1 & Average \\
\hline ix. & Provision of services on time with reasonable waiting time & 3.10 & 6 & Average \\
\hline
\end{tabular}




\begin{tabular}{|c|c|c|c|c|}
\hline $\mathrm{x}$. & $\begin{array}{l}\text { Easiness and convenience in patient registration and queue } \\
\text { management }\end{array}$ & 2.93 & 12 & Low \\
\hline xi. & Promptness in attending to patients' requests & 2.98 & 9 & Low \\
\hline xii. & The willingness of staff to help customers all the time & 2.95 & 11 & Low \\
\hline xiii. & Staff is knowledgeable and competent to provide OPD services & 3.07 & 7 & Average \\
\hline xiv. & $\begin{array}{l}\text { Staff being trustworthy and Patients feeling safe while being } \\
\text { treated at the OPD }\end{array}$ & 2.96 & 10 & Low \\
\hline $\mathrm{xv}$. & Staff is polite and respecting the privacy of patients & 2.93 & 12 & Low \\
\hline xvi. & Staff paying individual attention to the patients & 2.81 & 15 & Low \\
\hline xvii. & Staff is aware of the specific needs of the patients & 2.84 & 14 & Low \\
\hline cviii. & Staff acting for the best interest of the patient & 2.76 & 17 & Low \\
\hline xix. & $\begin{array}{l}\text { Adequacy of time given to discuss patients' matters at the OPD } \\
\text { and }\end{array}$ & 2.78 & 16 & Low \\
\hline $\mathrm{xx}$. & Functioning the OPD at convenient hours to all patients & 2.73 & 18 & Low \\
\hline
\end{tabular}

None of the items was perceived to have 'high' level of service quality. Highest perceived quality was recorded for 'providing service right first time' which had an average level of perceived quality. Functioning the OPD at convenient times for all patients had the least perceived quality. All items in tangibility dimension had an average level of quality while all items in the empathy dimension were 'low'. Eleven out of 20 items had 'Low' service quality as perceived by the respondents.

Figure 03 shows the detailed analysis of patents' expectations based on the frequency of the responses for each item of service quality in all five service quality dimensions 


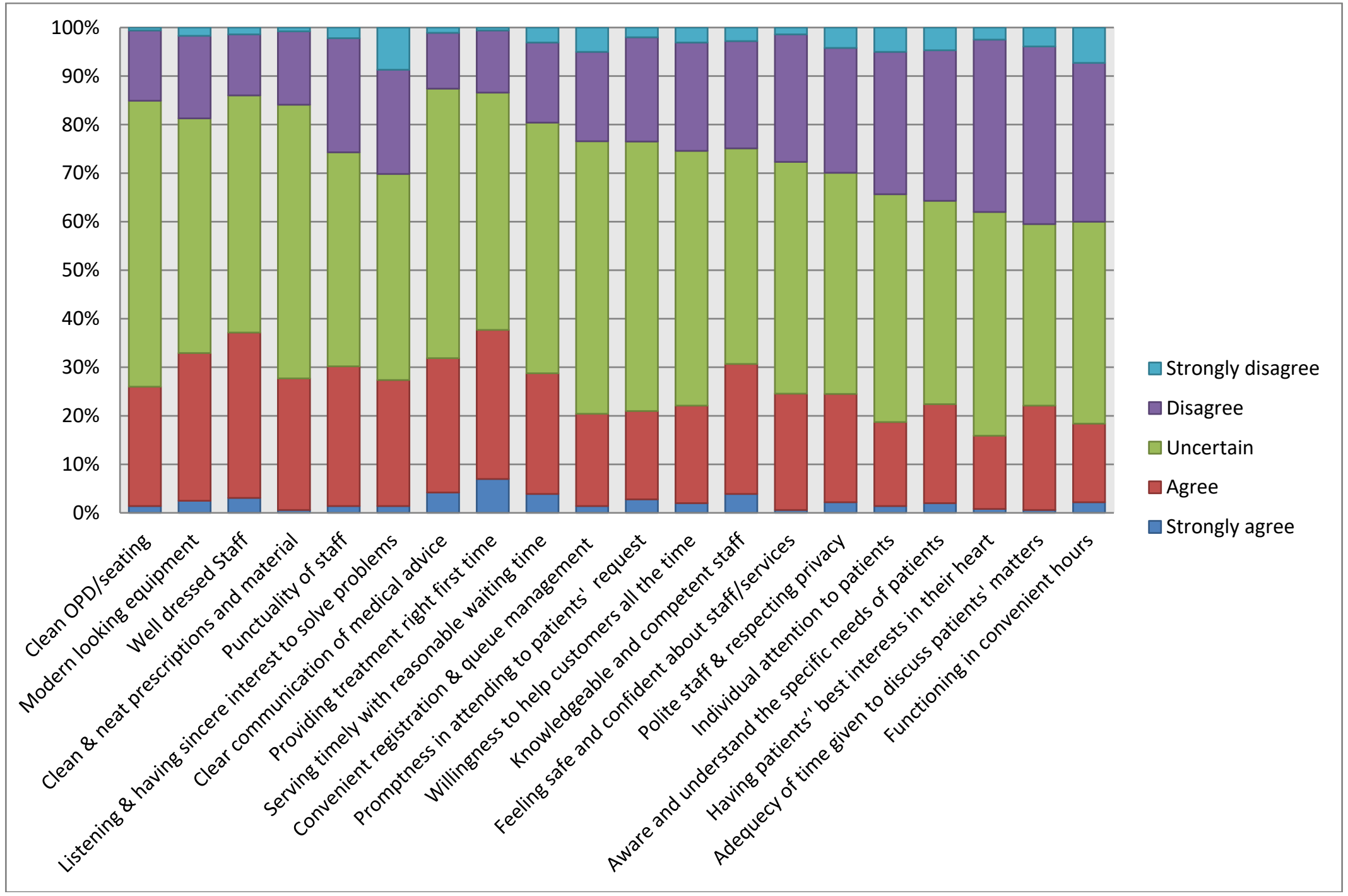

Figure 03: patients' perception regarding service quality (Author generated based on survey data) 
Seven percent of the respondents strongly agreed that the DGH Kegalle provided correct treatment first time (37.7\%). Less than 5\% of the respondents were in strong agreement that the OPD possessed all the other items of service quality. Least perceived service quality was for operating the OPD at a convenient time. Perceived quality never reached 'high' level for any of the items of service quality concerning the frequency of the responses. Only providing treatment right the first time (37.4\%) and Staff being well dressed (37.2\%) were perceived to be present in 'average' levels in OPD of DGH - Kegalle. While all the other items had 'low' perceived level of quality, lowest quality (15.9\%) was perceived in 'staff is having the best interest of the patients in their hearts.

\subsection{Service quality gaps}

The service quality gap was determined by calculating the Service quality Gap score as described in data analysis subsection in chapter 3 .

Table 11: Distribution of service quality gap score according to the service quality dimension

\begin{tabular}{lllll}
\hline $\begin{array}{l}\text { Service quality } \\
\text { dimension }\end{array}$ & $\begin{array}{l}\text { Mean Perception } \\
\text { Score }\end{array}$ & $\begin{array}{l}\text { Mean Expectation } \\
\text { Score }\end{array}$ & $\begin{array}{l}\text { Service Quality gap } \\
\text { score }\end{array}$ & Rank \\
\hline Tangibility & 3.16 & 4.05 & -0.89 & 5 \\
Reliability & 3.12 & 4.08 & -0.96 & 4 \\
Responsiveness & 2.99 & 4.01 & -1.02 & 2 \\
Assurance & 2.97 & 3.97 & -1.00 & 3 \\
Empathy & 2.78 & 3.96 & -1.18 & 1 \\
\hline Total Score & 3.00 & 4.02 & -1.02 & \\
\hline
\end{tabular}

All five dimensions showed a significant negative service quality gap indicating that the patients' expectations were always more than the perceived service quality. The widest gap was observed in Empathy dimension (-1.18). Tangibility dimension had the least gap which was -0.89 . Overall service quality gap was -1.02 . Neither zero no positive service quality gaps were present indicating 'poor' service quality in OPD services.

The service quality gap is presented in the following radar diagram. 


\section{Service Quality Gap}

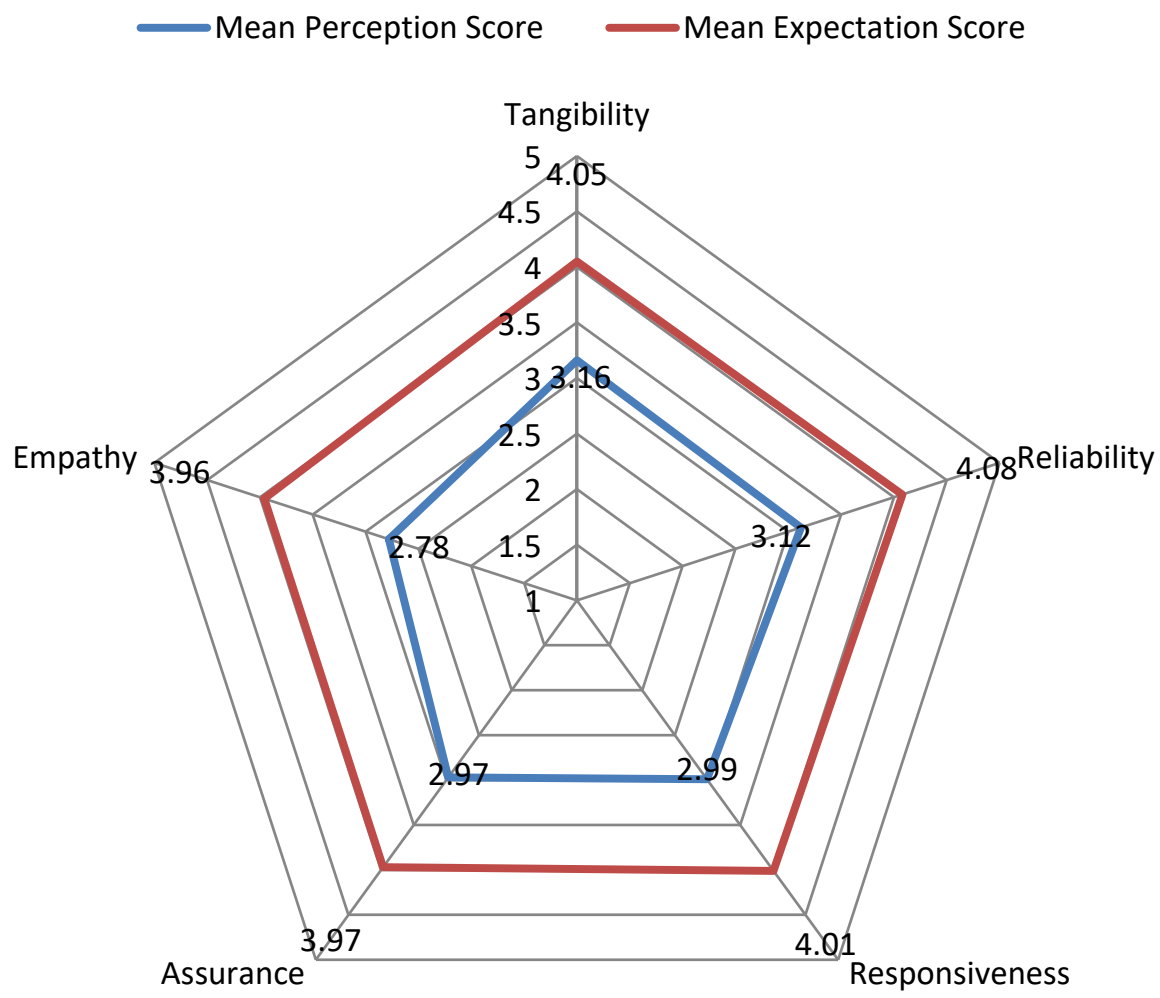

Figure 04: Distribution of service quality gaps according to service quality dimensions (Author generated based on survey data)

The gap between the lines representing the mean expectation score and the mean perception score clearly shows the service quality gap in OPD services in Kegalle hospital. The highest gap was seen in the empathy dimension.

Table 12: Service quality Gap score according to items

\begin{tabular}{llllll}
\hline $\begin{array}{l}\text { Service quality } \\
\text { dimension }\end{array}$ & Item number & $\begin{array}{l}\text { Mean } \\
\text { Perception } \\
\text { Score }\end{array}$ & $\begin{array}{l}\text { Mean } \\
\text { Expectation } \\
\text { Score }\end{array}$ & $\begin{array}{l}\text { Service Quality } \\
\text { gap score }\end{array}$ & Rank \\
\hline \multirow{3}{*}{ Tangibility } & Q1 & 3.12 & 4.00 & -0.88 & 14 \\
& Q2 & 3.15 & 4.03 & -0.88 & 14 \\
& Q3 & 3.25 & 4.1 & -0.85 & 15 \\
& Q4 & 3.12 & 4.07 & -0.95 & 11 \\
\hline \multirow{3}{*}{ Reliability } & Q5 & 3.04 & 4.18 & -1.14 & 5 \\
& Q6 & 2.90 & 4.15 & -1.25 & 1 \\
& Q7 & 3.22 & 3.94 & -0.72 & 17 \\
& Q8 & 3.31 & 4.05 & -0.74 & 16 \\
\hline \multirow{6}{*}{ Q9 } & 3.10 & 4.00 & -0.9 & 13 \\
& Q10 & 2.93 & 4.02 & -1.09 & 7 \\
\hline
\end{tabular}




\begin{tabular}{llllll}
\hline \multirow{2}{*}{ Responsiveness } & Q11 & 2.98 & 4.02 & -1.04 & 8 \\
& Q12 & 2.95 & 3.98 & -1.03 & 9 \\
\hline \multirow{3}{*}{ Assurance } & Q13 & 3.07 & 4.05 & -0.98 & 10 \\
& Q14 & 2.96 & 3.90 & -0.94 & 12 \\
\hline \multirow{5}{*}{ Empathy } & Q15 & 2.93 & 3.97 & -1.04 & 8 \\
& Q16 & 2.81 & 3.93 & -1.12 & 6 \\
& Q17 & 2.84 & 4.0 & -1.16 & 4 \\
& Q18 & 2.76 & 3.97 & -1.21 & 3 \\
& Q19 & 2.78 & 3.94 & -1.16 & 4 \\
\hline
\end{tabular}

(Author generated based on survey data)

Highest gap (1.25) was observed in listening to the patients' problems and showing sincere interest to solve them. Least gap was observed in communicating medical advice clearly and correctly to the patients $(0.72)$. All items in the Empathy dimension had a gap score less than - 1.00 suggesting a significant negative gap in service quality. However, all items in tangibility were more than -1.0 indicating lesser negative gap. 


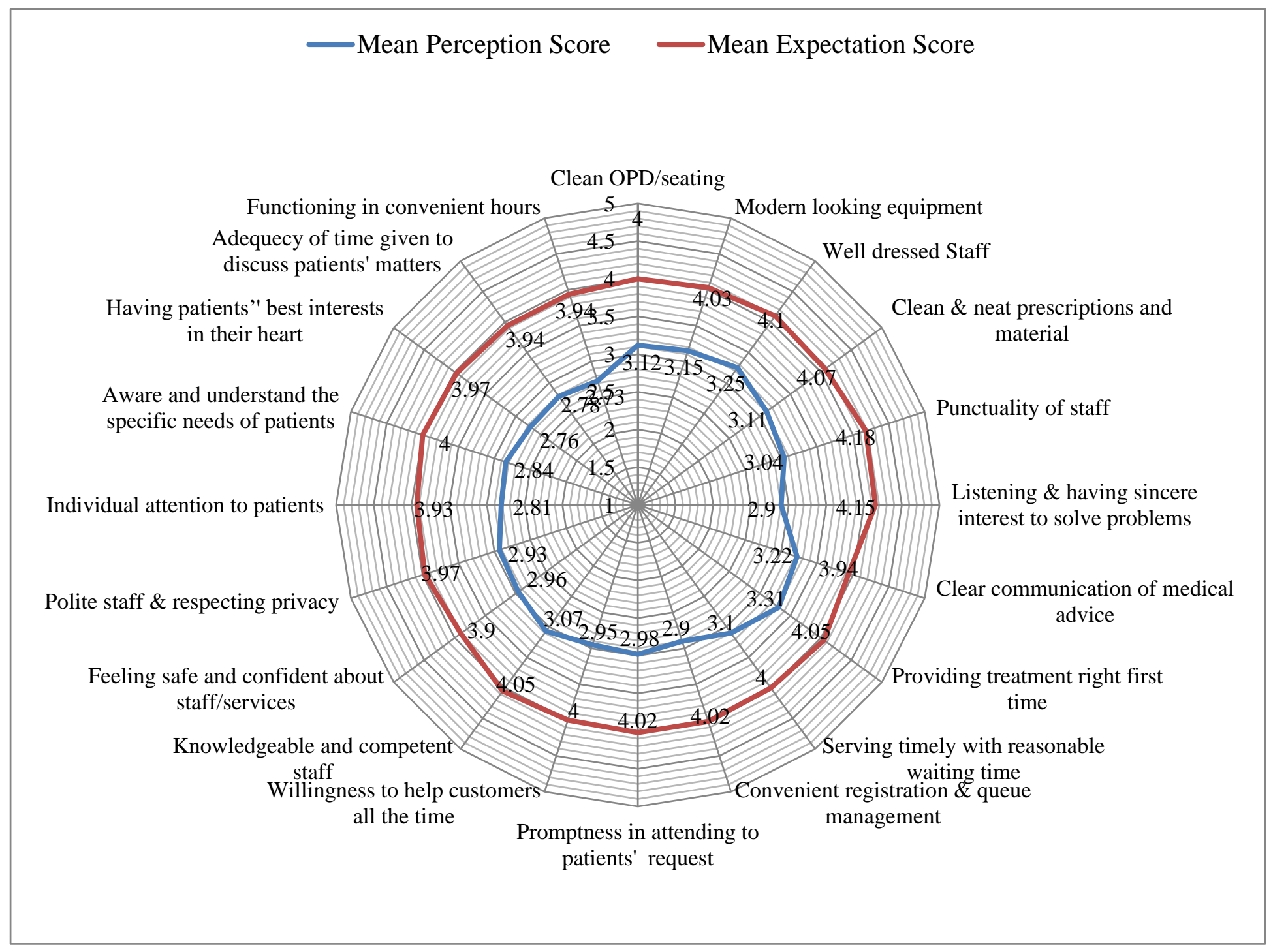

Figure 05: Distribution of service quality gap according to items (Author generated based on survey data) 


\section{CONCLUSION}

\section{Summary of outcomes and comments Overall service quality}

Overall service quality expectation was 'high' while the perceived service quality was 'average'. The negative service quality gap was significant for overall service quality and for all five dimensions of service quality also showed negative gap scores. These findings were compatible with the study in Tanzania (Khamis and Njau, 2014), India (Chakravarthy, 2011) and Iran (Zarei et al., 2012). Improved educational level, technological advancement, high internet and smart mobile device usage have allowed the patients to be more aware of disease conditions, patients' rights. Hence, patients are more demanding compared to the past and 'high' level of expectations' can be explained by this.

The study findings suggest that in comparison to the rise in expectations the actual perceived quality is low. This may have been caused by several reasons. A traditional 'physician-centered system' still prevails in the government health sector in Sri Lanka. Hence, expansions of health care services have focused more on the technical quality of services. Being a developing country and healthcare provided as a 'welfare service' free of charge, the funds allocated for healthcare development are limited. As priority is given to improve the technical quality and expansion of services, attention to basic amenities, toilet facilities, seating, and appearance of the hospital infrastructure etc. are often neglected by hospital management. Lack of soft skill development during induction training and in-service service may have contributed to this. Neglect of non -medical and emotional needs of patients may have caused a negative gap despite providing good clinical care.

\section{Empathy dimension}

Empathy dimension had the widest service quality gap (-1.18). Interestingly, patients' expectations and perceptions recorded lowest for this dimension. OPD services are provided from $8 \mathrm{am}$ to $4 \mathrm{pm}$ in DGH -Kegalle and many other government hospitals on weekdays. On Saturdays, it is functioning from $8 \mathrm{am}$ to 12 noon and Sundays from 8am to 10am. Therefore, working patients and school children cannot attend OPD without inconvenience. Functioning the OPD at nighttime and holidays is currently restricted by the shortage of human resource.

\section{Responsiveness dimension}

Responsiveness had the second widest negative gap. It was ranked third in both expectations and perception. Staff shortage and overcrowding of OPD has resulted from long waiting times in the queues and negatively affected the timely delivery of services. Further, DGH- Kegalle has a manual patient registration system and a queue management system which causes further delays.

\section{Assurance dimension}

Third widest gap was observed in assurance dimension while it was ranked $4^{\text {th }}$ in both expectations and perception. Lack of privacy and politeness of staff have mostly contributed to this negative gap. Poor communication skills of the staff, stress caused by overcrowding in both staff and patients may have contributed for this. Further, OPD space is maximally utilized to accommodate the number of services, privacy measures are compromised as a result.

\section{Reliability dimension}

Reliability dimension had the $4^{\text {th }}$ widest gap in service quality. However, the highest expectations and second-highest perceived quality was recorded in this dimension. Therefore, it is relatively satisfactory compared to the above-mentioned dimensions. However, still, a negative gap is observed which may have been caused by staff not being punctual and not listening to patients and not showing sincere interest to solve patients' problems. Staff shortage and overcrowding and poor communication skills may have played a role in this observation.

\section{Tangibility dimension}

Least service quality gap was observed for tangibles (-0.89). However, it was also a negative gap. The expectations were ranked second while the highest perceived quality was observed intangibles. Cleanliness and appearance of OPD, the appearance of equipment and material may have caused the observed gap.

\subsection{Discussion on the extension of existing knowledge}

The existing knowledge regarding service quality was gathered from different studies done in different parts of the world. Critically reviewing the existing knowledge showed that patients service quality needs were not fulfilled up to their expectations in most studies. Most studies concluded that the overall service quality was lower than expected in India, Iran, Ethiopia, Europe etc. The present study also found a similar trend where the overall service quality was poorer than expected by the patients. This is an eye-opener for the Sri Lankan health sector as its portraits the current deficiencies in OPD services.

Despite occasional items that showed positive service quality gaps leading to' patient delight, most studies showed negative service quality gaps in all five dimensions, some being statistically significant. This study also revealed a similar trend where all five dimensions showed a significant negative gap in service quality. This paves the path to evidence-based resource allocation and planning 
of healthcare services. The new knowledge gathered from this exercise lays the foundation for effective and sustainable improvement of OPD services.

\section{Suggestions for further research}

The present study intended to assess 384 patients. However, a $6.77 \%$ non-responder rate was observed which would have influenced the study findings. Hence, further research is recommended with many patients for better results. Further, the study was conducted in a single hospital. Hence the generalizability is limited. Future research involving the number of hospitals would help develop an understanding of the OPD service quality in Sri Lanka.

As healthcare is a 'service' not a 'product', the role of the health care personnel is important for the service quality. Unless patients' expectations are clearly understood by the health care personnel it will act as a bottleneck to improve service quality. Hence, it is suggested to assess the opinion and perception of doctors, nurses, pharmacists, paramedical staff and health care assistants etc. regarding the patients' expectations in service quality in future research.

The present study identified significant gaps in service quality in OPD services. The goal of the extension of knowledge is to improve the service quality of OPD services. List of recommendations is described in Chapter 6 of this report. Hence, an interventional study is proposed to implement the recommendations and to assess the effectiveness of the recommendations in improving the service quality.

The findings of the present study and the studies examined in the literature review showed that 'service quality' of the outpatient care services was mostly assessed based on SERVQUAL model or modified SERVQUAL model. Even the studies that have not adopted this model had assessed items about the appearance of infrastructure, the appearance of staff, responsiveness, individual attention, privacy and assurance etc. Further, the importance of obtaining informed written consent for treatment, infection control measures, health education and health promotion activities and having access to the social and family network while being treated' have also become important in the present era. Hence, the 'service quality' dimensions should be reevaluated and modified to include all these aspects through inductive research to build the latest models of service quality.

\section{Personal Reflections}

Completion of this report as partial fulfillment of requirements needed for the master's in business administration degree was a challenging and motivating experience. By conducting this study and writing this consultancy report I was able to gain a good insight regarding research methodology and academic writing. Reviewing literature helped me in gaining wide knowledge about the existing knowledge regarding service quality, possible research methods applicable to the study and it improved my critically reviewing skills. Answering the research questions and achieving the objectives of the study helped to extend the knowledge regarding service quality in the local context which was very rewarding. As a medical administrator by profession, it is very useful for my career as improving the healthcare service quality is one of my responsibilities in day-to-day work. Further, this will help the fellow medical administrators and fellow researchers to improve the service quality in their institutions and further expand the knowledge through research.

The main healthcare provider in Sri Lanka is the government healthcare service. All the healthcare services provided by the government hospitals including medical and surgical procedures are provided free of charge to the people of Sri Lanka. Therefore, the government health services are often criticized despite giving good clinical care which is evident by daily news and media reports. I believe the findings of this study will both health care personnel and the administrators to give due attention to these neglected aspects of service quality.

Finally, this exercise helped to improve my communication skills, interpersonal skills, time management skills and skills in balancing my studies, work commitments and personal life.

\section{RECOMMENDATIONS}

\section{Recommendation 01}

It is recommended to conduct surveys periodically to assess the patients' expectations and perceptions regarding service quality. The hospital quality management and planning unit staff can be assigned for this task. Placing a complaint and suggestion box in various places in the OPD or displaying an email/ telephone or mobile phone number in the OPD dedicated to accepting such complaints are also low-cost measures that can be implemented in the hospital. A quality management review committee including hospital managers, clinicians and other staff categories etc. needs to be established to review these complaints and suggestions monthly and to take remedial action.

\section{Recommendation 2}

It is recommended to incorporate soft skill development programmes for all the categories of OPD staff to the institutional inservice training programme. Further, awareness regarding the service quality needs to be increased among staff through these programmes as they are more focused on technical quality.

\section{Recommendation 3}

Hospital administration needs to regularly monitor and evaluate the OPD services and supervise the staff to be punctual, provide timely services and appear neat and clean. Often it is observed the OPD is understaffed leading to overwork and stress. This reduces service quality significantly. Care should be taken to provide an adequate number of staff with the necessary skills to OPD based on the number of OPD visits and procedures carried out. Assigning more staff for peak hours is also an option to overcome this deficiency.

\section{Recommendation 4}

This publication is licensed under Creative Commons Attribution CC BY.

http://dx.doi.org/10.29322/IJSRP.11.01.2021.p10985

WWw.ijsrp.org 
However, OPD of several hospitals has implemented digitalized medical record systems under 'the digital health project'. This has been successful in reducing the waiting time significantly while easy registration and easy retrieval of medical records have increased the continuity of care and easy follow-up. Furthermore, the electronic-based queue management system can also be successfully implemented along with the digital health project to make queue management more convenient for the patients.

\section{Recommendation 5}

It was observed that all items of the empathy dimension had low levels of perceived quality. The OPD currently operates on a first-come-first-served basis. Establishment of an appointment system through an online system or mobile messaging can reduce the waiting time for the working patients, school children etc. Operating a separate counter for the elderly, establishing disability access in the OPD, establishing a feeding area for lactating mother etc. may help to cater to the specific needs of patients. Establishment of reception and an inquiry desk in the OPD will ensure convenient and faster responses for patients' problems.

\section{Recommendation 6}

It is recommended for the hospital administrators and the fund allocators not only to allocate funds for expansion of services but also to give priority to the maintenance of hospital infrastructure, improving seating capacity and sanitary facilities etc. which are also not up to the expectations of the patients. Regular preventive and corrective maintenance of medical equipment would not only ensure better readings and results but also makes them visually appealing to the patients. Proper waste management, infection control measures and janitorial services will contribute to improving the tangibility dimension of service quality.

\section{Recommendation 7}

The study findings are generalizable to other district general hospitals in the country as many similarities are seen in the network of government hospitals in the country. The scope of hospital management is at times limited in improving service quality as certain factors are beyond the control of hospital management. Training medical students, pupil nurses and paramedical staff for government service are controlled by the university grant commission and Ministry of health. Therefore, incorporating behavioral science, communication skills, and interpersonal skills to these curriculums from the beginning is recommended to the authorities responsible for the education of the health care workers. Irregularities in the recruitment of health care personnel suitable for the jobs need to be corrected to continuously supply adequate human resource to the hospitals. Hence, the author recommends the ministry of health to pay special attention to these aspects through the findings of the study.

Identify the constructs of a Journal - Essentially a journal consists of five major sections. The number of pages may vary depending upon the topic of research work but generally comprises up to 5 to 7 pages. These are:

1) Abstract

2) Introduction

3) Research Elaborations

4) Results or Finding

5) Conclusions

\section{In Introduction you can mention the introduction about your research.}

\section{IDENTIFY, RESEARCH AND COLLECT IDEA}

It's the foremost preliminary step for proceeding with any research work writing. While doing this go through a complete thought process of your Journal subject and research for it's viability by following means:

1) Read already published work in the same field.

2) Goggling on the topic of your research work.

3) Attend conferences, workshops and symposiums on the same fields or on related counterparts.

4) Understand the scientific terms and jargon related to your research work.

\section{WRITE DOWN YOUR STUDIES AND FINDINGS}

Now it is the time to articulate the research work with ideas gathered in above steps by adopting any of below suitable approaches:

\section{A. Bits and Pieces together}

In this approach combine all your researched information in form of a journal or research paper. In this researcher can take the reference of already accomplished work as a starting building block of its paper.

Jump Start

This approach works the best in guidance of fellow researchers. In this the authors continuously receives or asks inputs from their fellows. It enriches the information pool of your paper with expert comments or up gradations. And the researcher feels confident about their work and takes a jump to start the paper writing. 


\section{B. Use of Simulation software}

There are numbers of software available which can mimic the process involved in your research work and can produce the possible result. One of such type of software is Matlab. You can readily find Mfiles related to your research work on internet or in some cases these can require few modifications. Once these Mfiles are uploaded in software, you can get the simulated results of your paper and it easies the process of paper writing.

As by adopting the above practices all major constructs of a research paper can be written and together compiled to form a complete research ready for Peer review.

\section{GET PEER REVIEWED}

Here comes the most crucial step for your research publication. Ensure the drafted journal is critically reviewed by your peers or any subject matter experts. Always try to get maximum review comments even if you are well confident about your paper.

For peer review send you research paper in IJSRP format to editor@ijsrp.org.

\section{IMPROVEMENT AS PER REVIEWER COMMENTS}

Analyze and understand all the provided review comments thoroughly. Now make the required amendments in your paper. If you are not confident about any review comment, then don't forget to get clarity about that comment. And in some cases there could be chances where your paper receives number of critical remarks. In that cases don't get disheartened and try to improvise the maximum.

\section{After submission IJSRP will send you reviewer comment within 10-15 days of submission and you can send us the updated paper within a week for publishing.}

This completes the entire process required for widespread of research work on open front. Generally all International Journals are governed by an Intellectual body and they select the most suitable paper for publishing after a thorough analysis of submitted paper. Selected paper get published (online and printed) in their periodicals and get indexed by number of sources.

After the successful review and payment, IJSRP will publish your paper for the current edition. You can find the payment details at: http://ijsrp.org/online-publication-charge.html.

\section{CONCLUSION}

A conclusion section is not required. Although a conclusion may review the main points of the paper, do not replicate the abstract as the conclusion. A conclusion might elaborate on the importance of the work or suggest applications and extensions.

\section{APPENDIX}

Appendixes, if needed, appear before the acknowledgment.

\section{ACKNOWLEDGMENT}

The preferred spelling of the word "acknowledgment" in American English is without an "e" after the "g." Use the singular heading even if you have many acknowledgments.

\section{REFERENCES}

[1] G. O. Young, "Synthetic structure of industrial plastics (Book style with paper title and editor)," McGraw-Hill, 1964, pp. 15-64.

[2] W.-K. Chen, Linear Networks and Systems (Book style). Belmont, CA: Wadsworth, 1993, pp. 123-135.

[3] H. Poor, An Introduction to Signal Detection and Estimation. New York: Springer-Verlag, 1985, ch. 4.

[4] B. Smith, "An approach to graphs of linear forms (Unpublished work style)," unpublished.

[5] E. H. Miller, "A note on reflector arrays (Periodical style-Accepted for publication)," IEEE Trans. Antennas Propagat., to be published.

[6] J. Wang, "Fundamentals of erbium-doped fiber amplifiers arrays (Periodical style—Submitted for publication)," IEEE J. Quantum Electron., submitted for publication.

\section{AUTHORS}

First Author - Author name, qualifications, associated institute (if any) and email address. 
Second Author - Author name, qualifications, associated institute (if any) and email address.

Third Author - Author name, qualifications, associated institute (if any) and email address.

Correspondence Author - Author name, email address, alternate email address (if any), contact number. 